\title{
Electrooptic and Dielectric Studies in Cadmium Sulphide Nanorods/Ferroelectric Liquid Crystal Mixtures
}

\author{
Praveen Malik, ${ }^{1}$ Ashok Chaudhary, ${ }^{1}$ Rohit Mehra, ${ }^{1}$ and K. K. Raina ${ }^{2}$ \\ ${ }^{1}$ Liquid Crystal Research Laboratory, Department of Physics, Dr. B. R. Ambedkar National Institute of Technology, Punjab, \\ Jalandhar 144 011, India \\ ${ }^{2}$ Materials Research Laboratory, School of Physics and Materials Science, Thapar University, Punjab, Patiala 147 004, India
}

Correspondence should be addressed to Praveen Malik, pmalik100@yahoo.com

Received 13 August 2012; Accepted 31 August 2012

Academic Editor: Victor V. Moshchalkov

Copyright () 2012 Praveen Malik et al. This is an open access article distributed under the Creative Commons Attribution License, which permits unrestricted use, distribution, and reproduction in any medium, provided the original work is properly cited.

\begin{abstract}
We present the results based on the electrooptic and dielectric studies in cadmium sulphide (CdS) nanorods/ferroelectric liquid crystal mixtures. Doping of CdS nanorods increases the spontaneous polarization and response time, which due to large dipoledipole interaction and increase in anchoring energies exists between nanorods and FLC molecules. Dielectric measurements revealed a decrease $(\sim 40 \%$ for $0.3 \%$ CdS in FLC) in permittivity and dielectric strength in doped sample cell than pure FLC mixture. A decrease in dc conductivity and relaxation frequency with doping concentration was also noticed. The preexponent factor and fractional exponent factor are found as predicated by existing theories.
\end{abstract}

\section{Introduction}

Liquid crystal (LC) devices are indispensable elements of modern life because of ubiquity of their application like spatial light modulator, optical antennas, and flat panel display devices [1-7]. Nanomaterials as a doping agent into liquid crystalline materials have attracted great deal of attention due to their unique structure and physical properties. Recently, nanomaterials have been doped into LCs and studied for improvement in electro-optic and optical properties such as enhanced photoluminescence, higher polarization, fast response time, low operating voltage, and improved conductivity [8-17]. For enhancing the physical properties, a proper selection of nanomaterials for liquid crystals depends upon various factors such as size, shape, preparation methods, surfactant concentration, and amount of doping materials $[18,19]$. The semiconductor nanoparticles $\left(\mathrm{TiO}_{2}, \mathrm{ZnO}, \mathrm{CdS}\right.$, etc.) have been studied for improved physical properties [20-23]. Kinkead and Hegmann observed that the effect of size and capping agent and concentration of CdSe and CdTe quantum dots play an important role to modify the electro-optic properties [23]. The advantage of nanorods over other materials is that nanorods are aligned in the direction of LCs molecules and give more alignment for better electro-optical responses. Due to the high anisotropic nature of nanorods, they can be excellent candidate for the application of optoelectronic devices. Various studies confirm that doping of nanorods (Cds, ZnS, CdSe, etc.) into nematic liquid crystals has considerable improvement in various properties such as optical, structural, electrooptic, and dielectric [24-29]. Earlier work was emphasized on nanorods-nematic liquid crystals; however, nanorodsferroelectric liquid crystal is rarely reported [30, 31].

In the present paper, an attempt has been made to study the effect of CdS nanorods on the electro-optic and dielectric properties in CdS/FLC mixtures.

\section{Experimental}

Synthesis of cadmium sulphide nanorods Initially cadmium oxide (CdO, $0.21 \mathrm{~g})$, n-octadecylphosphonic acid (ODPA, $1.07 \mathrm{~g}$ ) and tri-n-octylphosphine oxide (TOPO, $2.9 \mathrm{~g}$ ) were properly mixed and heated under argon at $100^{\circ} \mathrm{C}$ and then evacuated for $1 \mathrm{~h}$ to remove any moisture. This mixture was heated under argon upto $300^{\circ} \mathrm{C}$ to give a colourless solution. Now a solution of sulphur and trioctyphosphine was injected 


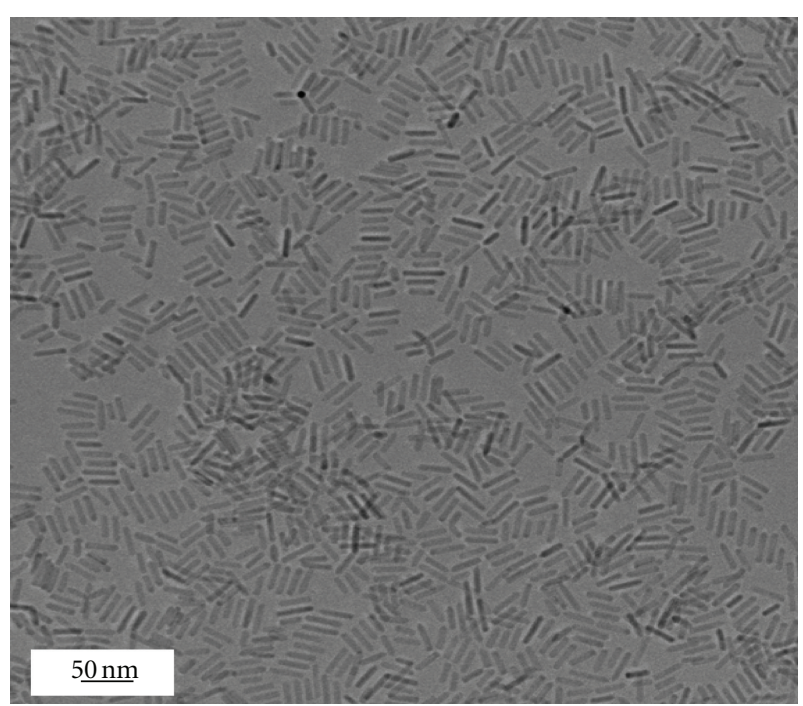

FIgURE 1: TEM image of CdS nanorods.

in prepared mixture and the nanocrystals were allowed to grow for $30 \mathrm{~min}$ before removal of the heating mantle. When the solution achieved a temperature of $60^{\circ} \mathrm{C}$, then $5 \mathrm{~mL}$ of toluene was added. The CdS nanorods were purified 3-5 times by repeated dissolution in toluene: methanol mixture. The nanorods were stored in toluene. The TEM image of $\mathrm{CdS}$ nanorods (size $7 \times 50 \mathrm{~nm}$, width $\times$ length) is presented in Figure 1. The detailed synthesis of CdS nanorods is also reported in previously published methods [32].

In this study, ferroelectric liquid crystal material (KCFLC10R, Kingston Chemicals, UK) has been used as host material. The spontaneous polarization of the FLC material is $23 \mathrm{nC} / \mathrm{cm}^{2}$, tilt angle is $22^{\circ}$, and optical birefringence is 0.18 at $25^{\circ} \mathrm{C}$. The phase sequence of material is as follows:

$$
K \stackrel{5^{\circ} \mathrm{C}}{\longrightarrow} \mathrm{SmC}^{*} \stackrel{64.5^{\circ} \mathrm{C}}{\longrightarrow} \mathrm{SmA} \stackrel{99.5^{\circ} \mathrm{C}}{\longrightarrow} N^{*} \stackrel{112^{\circ} \mathrm{C}}{\longrightarrow} I .
$$

Empty LC sample cells of thickness $4 \mu \mathrm{m}$ were prepared using indium tin oxide (ITO) coated transparent glass substrates of sheet resistance $24 \Omega / \square$. Four cells assigned as pure and doped FLC samples were prepared using doping of $\mathrm{CdS}$ in varying concentration of $0.0,0.1,0.2$, and $0.3 \mathrm{wt} / \mathrm{wt} \%$ ratio into FLC. The homogenized mixture of CdS and FLC was then filled between empty LC sample cells by capillary action at the isotropic temperature of FLC and finally sealed using norland optical adhesive (NOA-65). The electrodes were connected at the ITO surface of the cells using indium material. The sample cells were kept in a hot stage coupled with temperature controller (LINKAM-TP 95, THMSE 600) and can be stabilized to an accuracy of $0.5^{\circ} \mathrm{C} / \mathrm{min}$. The cooling and heating cycles were performed several times to obtain a better alignment. The change in phases was analyzed with the help of optical polarizing microscope (Nikon Eclipse LV100POL). The electro-optical responses were recorded on a digital storage oscilloscope (Tektronix TDS2024B). The dielectric measurements were performed in the frequency range of $50 \mathrm{~Hz}$ to $1 \mathrm{MHz}$ using LCR meter (Fluke- PM6306).

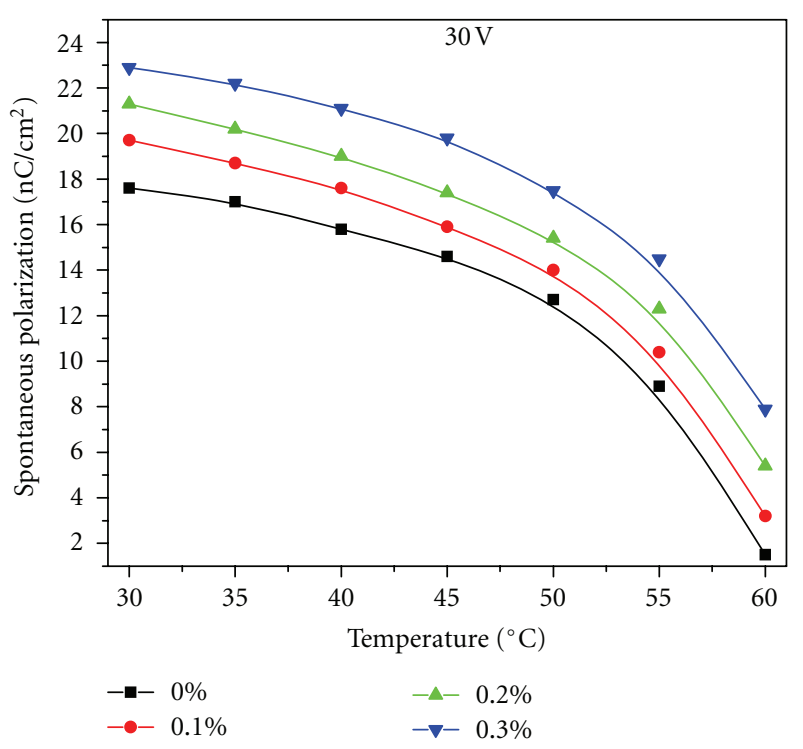

FIgure 2: Typical temperature versus spontaneous polarization for pure and CdS nanorods doped samples at 30 volts $(f=50 \mathrm{~Hz})$.

\section{Results and Discussion}

3.1. Electrooptic Studies. Figure 2 shows the temperature dependence on spontaneous polarization $\left(P_{s}\right)$ for pure and doped sample cells at $30 \mathrm{~V}$. It can be inferred from Figure 2 that polarization decreases with increasing the temperature and follows the first-order phase transition behaviour. Doping of CdS nanorods $(0.3 \%)$ in FLC increases the $P_{s}$ value $\sim 18 \%$ as compared to pure FLC sample. The increment in $P_{s}$ value in doped samples is due to contribution of additional dipole moment by nanorods. Here nanorods get aligned along the applied field and increase the polarization value. This increase in $P_{s}$ is also confirmed by the measurement of tilt angle $(\theta)$, as $P_{s} \propto \theta$. The tilt angle variation as a function of temperature is given in Figure 3. A slight increase in tilt angle in doped sample has been observed. This increase in tilt angle shows the strong coupling between nanorods and FLC molecules, which provides larger dipoledipole interaction between them. The higher value of dipole moment in doped samples shows a corresponding increase in spontaneous polarization. Figure 4 shows the behaviour of rotational viscosity $(\eta)$ with temperature in all sample cells at $30 \mathrm{~V}$. We found that the $\eta$ increases with increasing the concentration of CdS nanorods. It may be due to the increase in strength of dipolar interaction between the CdS nanorods and FLC molecules at the interface [21]. The increment in the tilt angle with respect to nanorods doping in pure FLC also supports the increase in the rotational viscosity. The electrooptic response time $\left(\tau_{s}\right)$ is calculated by using the relation

$$
\tau_{s}=\frac{\eta}{P_{s} \cdot E}
$$

where $E$ is the applied electric field. Temperature dependence on $\tau_{\mathrm{s}}$ for pure and doped samples at $30 \mathrm{~V}(50 \mathrm{~Hz})$ is plotted in Figure 5. $\tau_{s}$ decrease with increasing the temperature and nanorods concentration in doped samples than pure FLC 


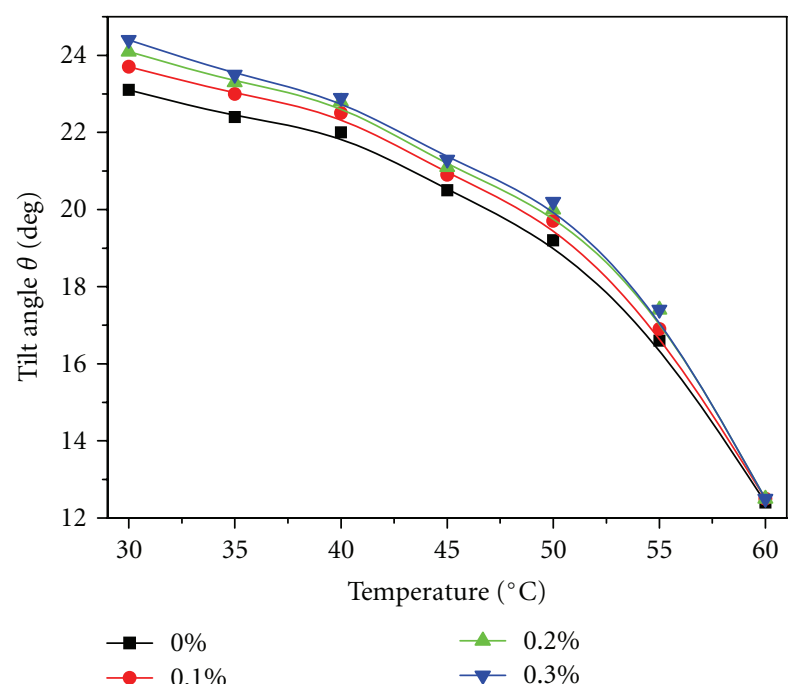

FIgURE 3: Behavior of tilt angle with temperature for pure and CdS nanorods doped samples.

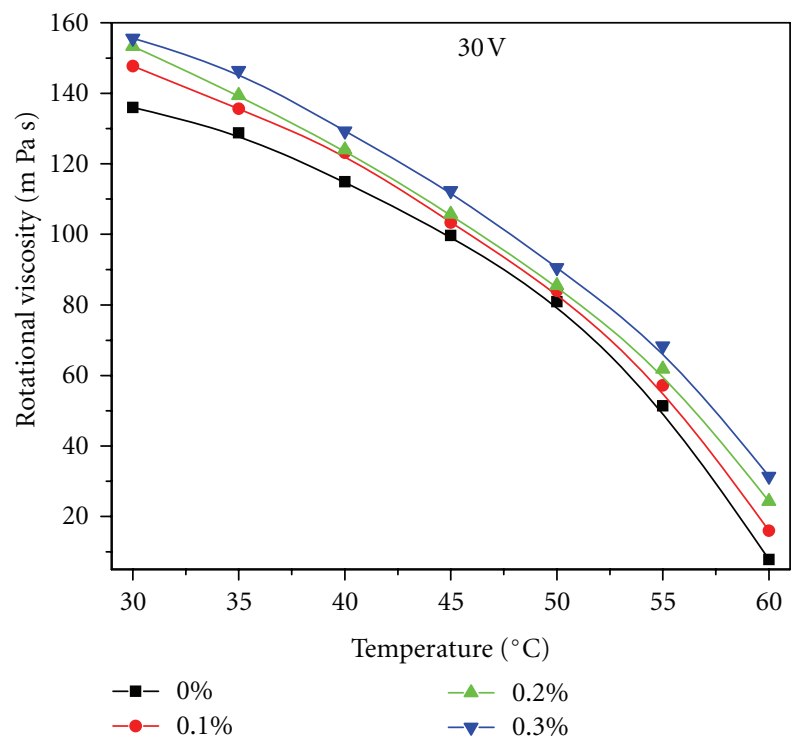

FIGURE 4: Variation of rotational viscosity with temperature for pure and CdS nanorods doped samples.

sample. As both the values $P_{s}$ and $\eta$ has been increased in case of doped samples, the combined effect of increased value of these parameters results a faster response time in doped samples (Figure 5). The modification in these electrooptic parameters in doped sample cells may be explained on anchoring phenomena. It has been reported that addition of nanorods increase the surface anchoring and hence corresponding effect on physical properties such as liquid crystal response time [25]. The LC response time relation

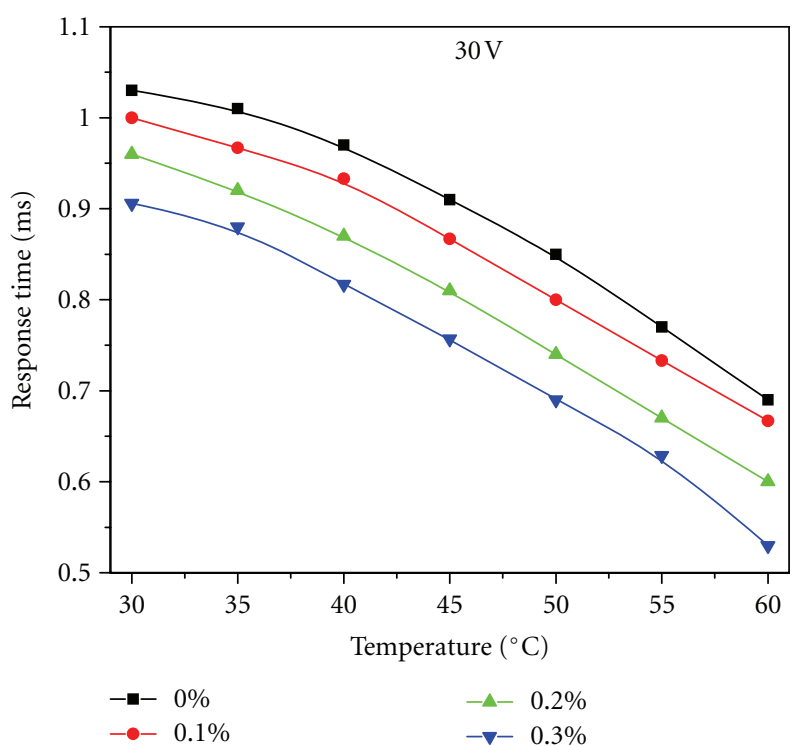

FIGURE 5: Temperature dependence on response time for pure and CdS nanorods doped samples.

with the anchoring energy in weak and strong anchoring conditions can be written as $[16,33]$

$$
\begin{gathered}
\tau_{s}=\frac{\eta}{K \pi^{2}}\left(d^{2}+\frac{4 d k}{W}\right) \quad \text { For strong anchoring, } \\
\tau_{s}=\frac{4 \eta d}{W \pi^{2}} \quad \text { For weak anchoring, }
\end{gathered}
$$

where $d$ cell thickness, $k$ bend elastic constant, and $W$ is anchoring energy coefficient. In both cases (strong and weak anchoring), the response time is inversely propositional to anchoring energies. It means that if the anchoring energy increases in doped sample cells that may lead to faster response time as predicated from (3).

3.2. Dielectric Studies. The study of dielectric properties provides the information of molecular structure and mechanism of molecular process. Generally during molecular process, two modes goldstone mode and soft mode appear. Goldstone mode appears in $\mathrm{SmC}^{*}$ phase because of phase fluctuation in the azimuthal orientation of the direction which shows up in low frequency range, whereas the soft mode dominates over the goldstone mode near transition temperature of SmC* and SmA phase and appears due to tilt fluctuation which is maximum near the transition temperature. The relationship between the complex dielectric permittivity can be written as [34-38]

$$
\varepsilon^{*}=\varepsilon^{\prime}-j \varepsilon^{\prime \prime},
$$

where $\varepsilon^{\prime}$ is the real part of the dielectric permittivity and $\varepsilon^{\prime \prime}$ is the imaginary part. In order to describe complex dielectric 


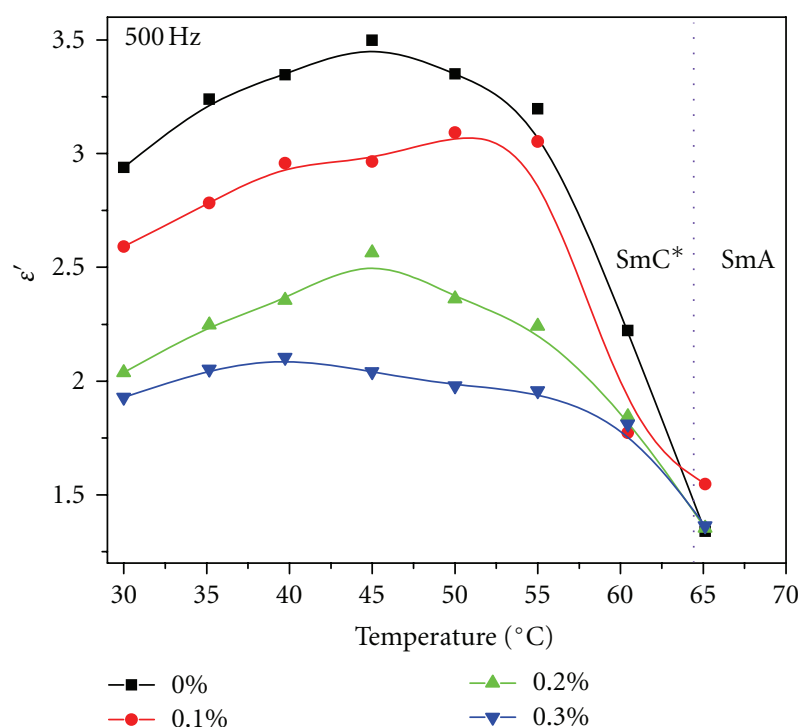

(a)

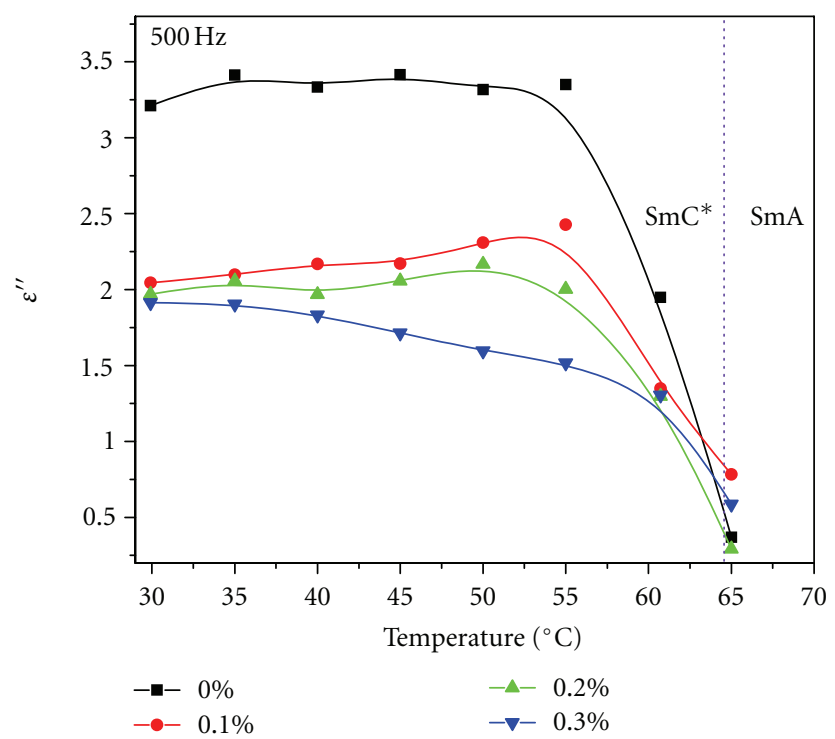

(b)

Figure 6: Temperature dependence on dielectric permittivity in pure and CdS nanorods doped samples at $500 \mathrm{~Hz}$ for (a) $\varepsilon^{\prime}$ and (b) $\varepsilon^{\prime \prime}$.

permittivity, $\varepsilon^{\prime}$ and $\varepsilon^{\prime \prime}$ can be characterized by the following Debye model:

$$
\begin{gathered}
\varepsilon^{\prime}=\varepsilon_{\infty}+\frac{\left(\varepsilon_{0}-\varepsilon_{\infty}\right)}{\left(1+\omega^{2} \tau^{2}\right)}, \\
\varepsilon^{\prime \prime}=\frac{\left(\varepsilon_{0}-\varepsilon_{\infty}\right) \omega \tau}{\left(1+\omega^{2} \tau^{2}\right)},
\end{gathered}
$$

where $\varepsilon_{0}$ is the low frequency limit of dielectric permittivity, $\varepsilon_{\infty}$ is the high frequency limit of dielectric permittivity, $\omega$ is the angular frequency of applied electric field, and $\tau$ is the relaxation time. The dielectric relaxation spectrum can be described with the help of the following generalised ColeCole equation as $[34,36,39]$

$$
\varepsilon^{*}=\varepsilon_{\infty}+\sum \frac{(\Delta \varepsilon)}{1+(j \omega \tau)^{1-\alpha}}+\frac{\sigma}{j \in_{o} \omega^{k}},
$$

where $\Delta \varepsilon, \alpha$, and $\sigma$ are dielectric strength, distribution parameter, and electric conductivity, respectively. $\epsilon_{o}$ is electric permittivity of free space. Temperature dependence on dielectric permittivities for pure and doped sample cells at $500 \mathrm{~Hz}$ is shown in Figures 6(a) and 6(b). Figure 6(a) shows that in each sample real part of permittivity more or less increases in $\mathrm{SmC}^{*}$ up to $\mathrm{SmC}^{*}$-SmA transition temperature $\left(T_{c}\right)$. A decrease in permittivity $(\sim 40 \%)$ is found in $0.3 \mathrm{wt} \%$ doped sample than pure FLC material. From Figure 6(b), it can be observed that $\varepsilon^{\prime \prime}$ also decreases with increase in concentration of CdS nanorods. Frequency dependence behavior on $\varepsilon^{\prime}$ and $\varepsilon^{\prime \prime}$ at $30^{\circ} \mathrm{C}$ is presented in Figure 7. Figure 7(a) infers that in higher doped samples, $\varepsilon^{\prime}$ decreases with increasing the nanorods doping concentration. However, at higher frequencies $(\geq 1 \mathrm{kHz})$, no significant variation in $\varepsilon^{\prime}$ has been observed. Figure 7(b) follows a typical absorption behavior observed for pure and doped samples. It can be seen from Figure 7(b) that permittivity continuously decreases with increasing doping concentration. A relaxation mode which appears at $\sim 300 \mathrm{~Hz}$ in pure FLC material slightly shifts to higher frequency $\sim 500 \mathrm{~Hz}$ for doped samples. Figure 8 demonstrated the Cole-Cole behavior of pure and doped samples in which only one relaxation mode, that is, goldstone mode (GM) has been clearly seen. The calculated value of distribution parameter was found in the range of 0 to 1 . The reduction in distribution parameter with the doping of CdS nanorods (Figure 8) suggests the Debye type relaxation behavior [31]. The behavior of relaxation frequency $\left(f_{r}\right)$ and dielectric strength $\left(\Delta \varepsilon_{\mathrm{GM}}\right)$ for pure and doped sample is shown in Figures 9 and 10, respectively. The complete behaviour of $f_{r}$ and $\Delta \varepsilon_{\mathrm{GM}}$ can be represented using Landau free energy expansion [30]

$$
\begin{gathered}
f_{r}=\frac{K_{33} q^{2}}{2 \pi \eta}, \\
\Delta \varepsilon_{\mathrm{GM}}=\frac{P_{s}^{2}}{2 \varepsilon_{o} K_{33} q^{2} \theta^{2}},
\end{gathered}
$$

where $K_{33}$ is the elastic constant and $q$ is the wave vector of helical structure of material. From (7) and (8), it is clear that $f_{r}$ depends only upon the $\eta$ and $q$, whereas $\Delta \varepsilon_{\mathrm{GM}}$ depends upon $P_{s}, q, \theta$, and $K_{33}$. Out of $P_{s}, q, \theta ; \eta$ also play an important role in guest host mixture [31, 40]. It is clearly seen in Figure 9 that value of relaxation frequency decreases with increasing the concentration of nanorods and corresponding increase in rotational viscosity. The observed behaviour of $f_{r}$ follows as suggested in (7). Figure 10 demonstrated that $\Delta \varepsilon_{\mathrm{GM}}$ decreases with increasing the concentration of nanorods over the pure FLC material. It is observed that $\Delta \varepsilon_{\mathrm{GM}}$ slightly increases with increasing the temperature in SmC* and then drops considerably to low value near $T_{c}$. 


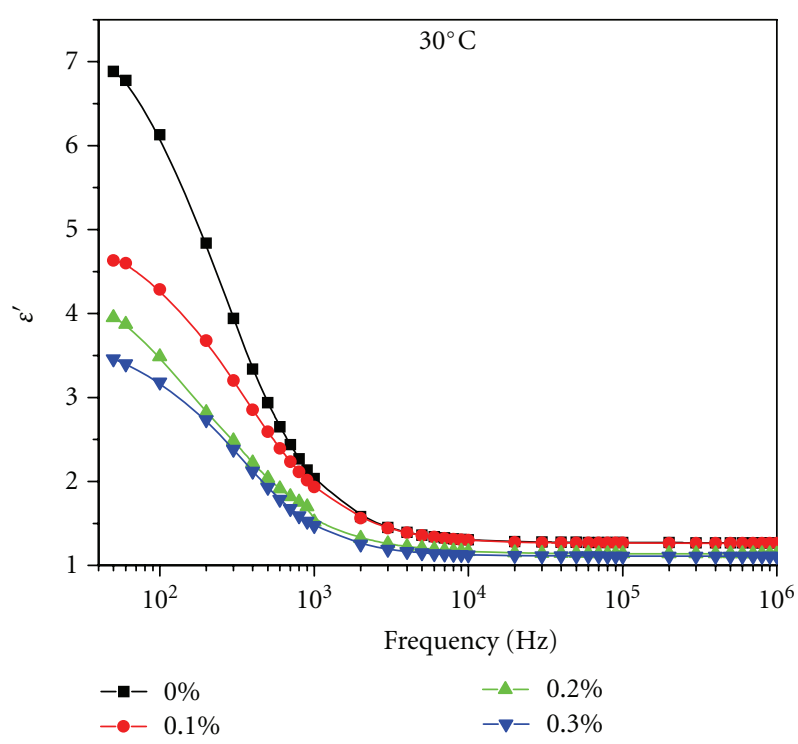

(a)

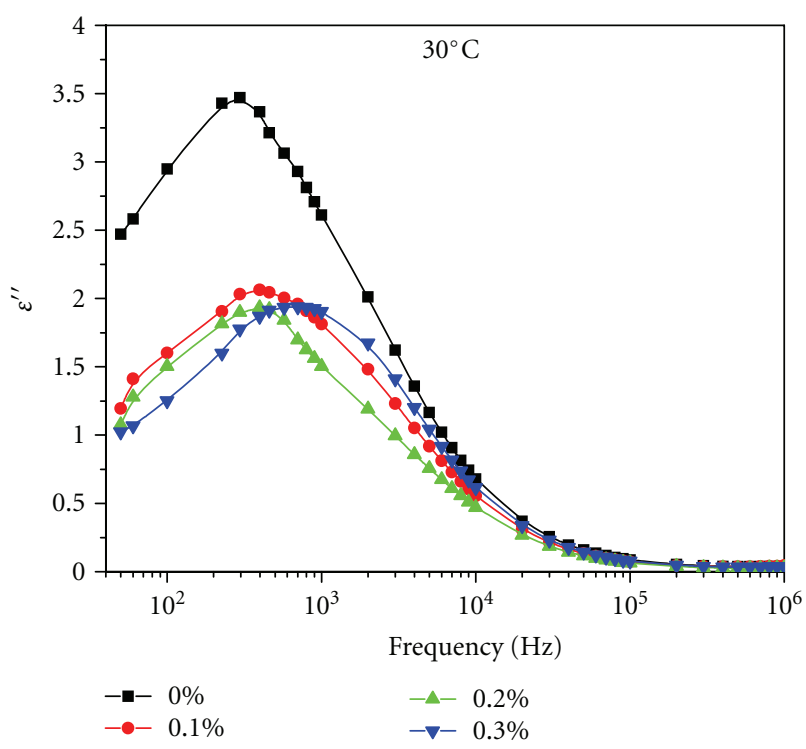

(b)

Figure 7: Frequency dependence on dielectric permittivity in pure and CdS nanorods doped samples at $30^{\circ} \mathrm{C}$ for (a) $\varepsilon^{\prime}$ and (b) $\varepsilon^{\prime \prime}$.

The frequency dependence on ac conductivity $\left(\sigma_{\mathrm{ac}}\right)$ is given by the relationship [41-43]

$$
\begin{gathered}
\sigma_{\mathrm{ac}}(\omega)=\varepsilon_{o} \varepsilon^{\prime \prime} 2 \pi f, \\
\sigma_{\mathrm{ac}}(\omega)=\sigma_{o}+A \omega^{n},
\end{gathered}
$$

where $\sigma_{o}$ is dc conductivity, $A$ is the preexponential factor, and $n$ is the fractional exponent lies between 0 and 1 . The values of $\sigma_{o}, A$, and $n$ were obtained by fitting the graph between ac conductivity and frequency from equation (10). The effect of nanorods concentration on dc conductivity at $30^{\circ} \mathrm{C}$ is shown in Figure 11. Figure 11 shows that $\sigma_{o}, A$, and $n$ decrease with doping of CdS nanorods, where $n$ is found

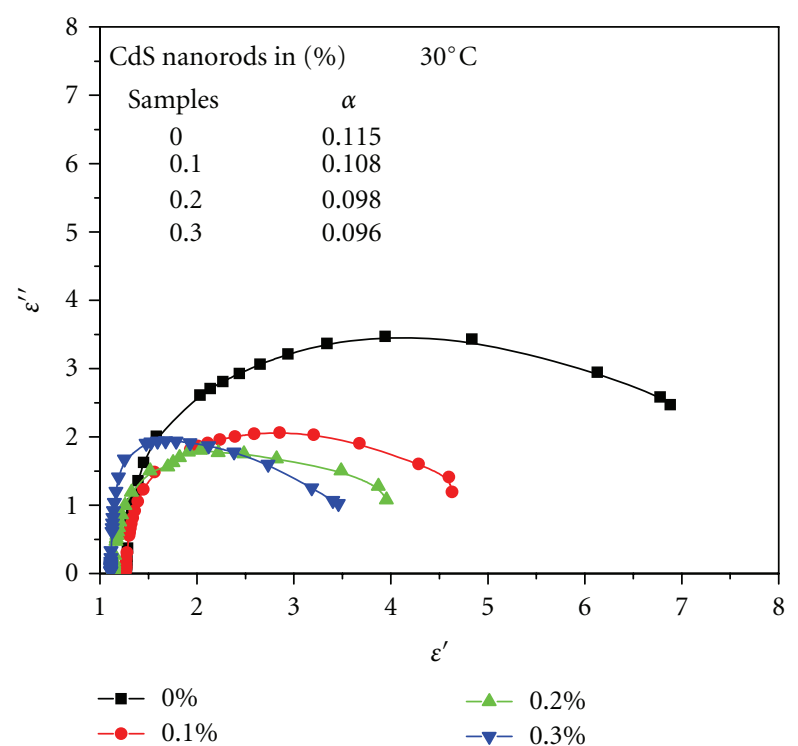

FIgure 8: Cole-Cole plots for pure and CdS nanorods doped samples at $30^{\circ} \mathrm{C}$.

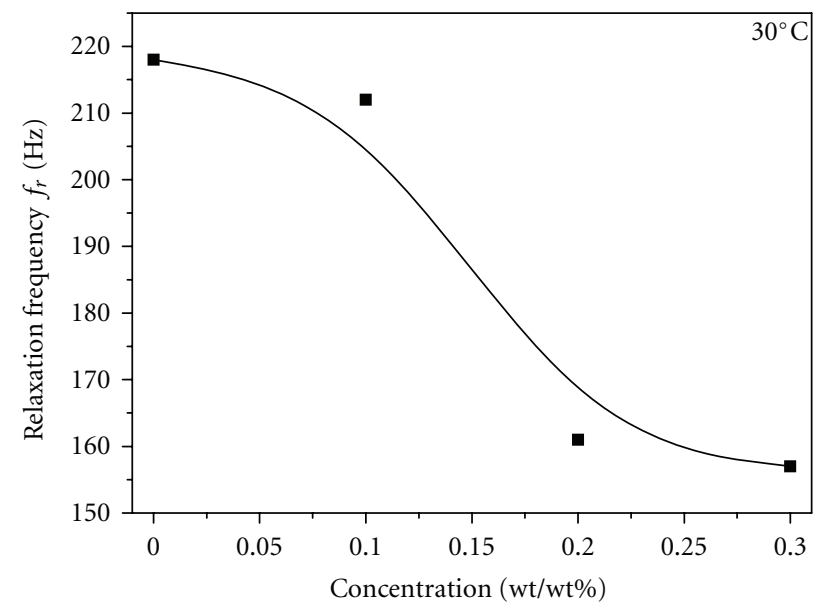

FIGURE 9: Behaviour of relaxation frequency of GM with nanorods concentration in $\mathrm{SmC}^{*}$ phase.

in the range from 0 to 1 . The activation energy $\left(E_{\tau}\right)$ for the dielectric relaxation was obtained by using the following Arrhenius relation:

$$
\tau=\tau_{o} \exp \left(-\frac{E_{\tau}}{k_{B} \cdot T}\right)
$$

where $\tau$ is the relaxation time, $\tau_{o}$ is the relaxation time at high temperature, $T$ the absolute temperature, and $k_{B}$ the Boltzmann constant. $\tau$ is the relaxation time and determined by the reciprocal of peak frequency as observed in Figure 7(b). The behaviour of activation energy with concentration of nanorods is also shown in Figure 12. The maximum activation energy for $0.3 \%$ doped sample over other samples indicates that high doping sample acquires maximum energy to realize the rotational motion. The calculated physical 
TABLE 1: Physical parameters of pure and CdS nanorods doped FLC sample cells at $30^{\circ} \mathrm{C}$.

\begin{tabular}{lccccccc}
\hline Samples $(\mathrm{CdS}$ nanorods in \%) & $P_{s}\left(\mathrm{nC} / \mathrm{cm}^{2}\right)$ & $\tau_{s}(\mathrm{~ms})$ & $\eta(\mathrm{m} \mathrm{Pas})$ & $\theta(\mathrm{deg})$ & $\Delta \varepsilon_{\mathrm{GM}}$ & $f_{r}(\mathrm{~Hz})$ & $E_{\tau}(\mathrm{eV})$ \\
\hline 0.0 & 17.6 & 1.03 & 135.96 & 23.1 & 8.0 & 218 & 0.210 \\
0.1 & 19.7 & 1.00 & 147.75 & 23.7 & 4.8 & 212 \\
0.2 & 21.3 & 0.96 & 153.36 & 24.1 & 4.7 & 161 \\
0.3 & 22.9 & 0.90 & 155.60 & 24.4 & 3.7 & 157 & 0.211 \\
\hline
\end{tabular}

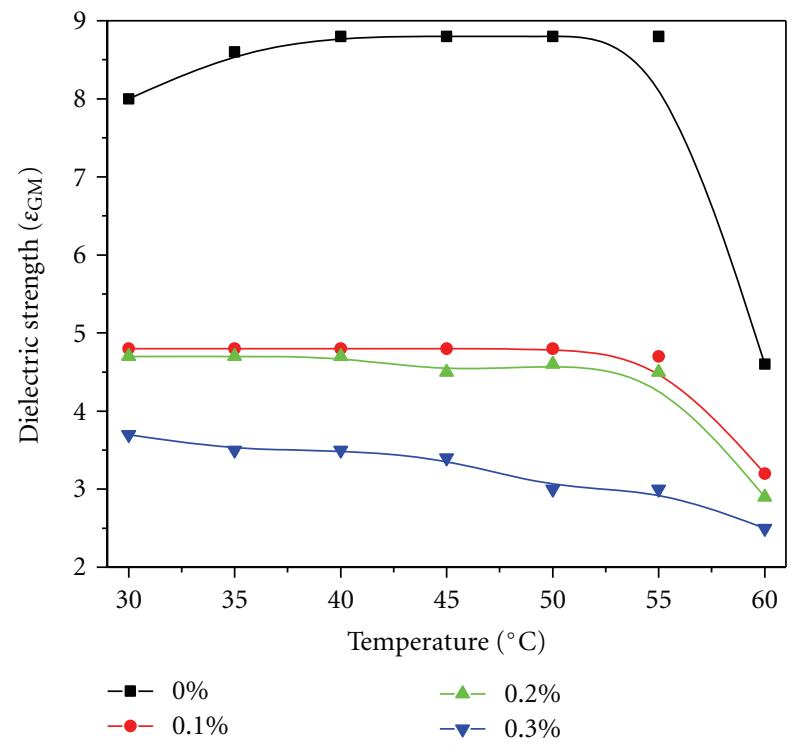

FIGURE 10: Temperature dependence of dielectric strength for pure and doped samples.

parameters obtained at $30^{\circ} \mathrm{C}$ from the above studies are also given in Table 1.

\section{Conclusions}

(i) The effect of CdS nanorods doping into ferroelectric liquid crystal mixture have been studied using electro-optic and dielectric measurements. Doping of CdS improves the response time and spontaneous polarization than pure FLC mixture and is due to the significant increase in dipole moment of FLC molecules.

(ii) A decrease in dielectric permittivity $(\sim 40 \%)$ was also noticed in the CdS doped samples than pure FLC mixture.

(iii) Dielectric strength and relaxation frequency decrease with increasing the concentration of nanorods and show a sharp transition near SmC-SmA transition temperature.

(iv) The activation energy slightly increases with CdS concentration and has maximum value for $0.3 \%$ doped FLC mixture.

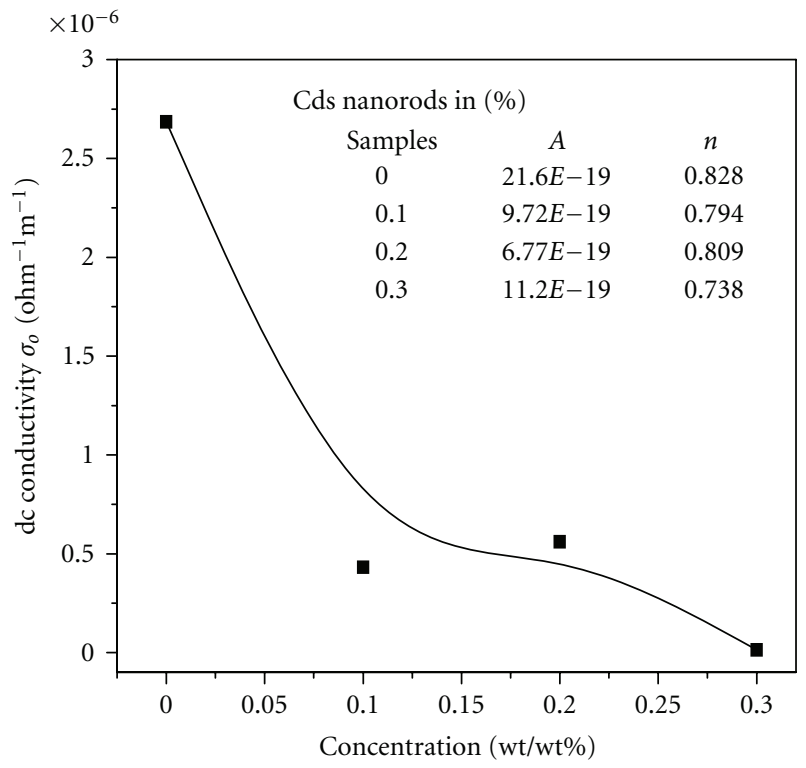

FIGURE 11: Variation of dc conductivity with nanorods concentrations at $30^{\circ} \mathrm{C}$.

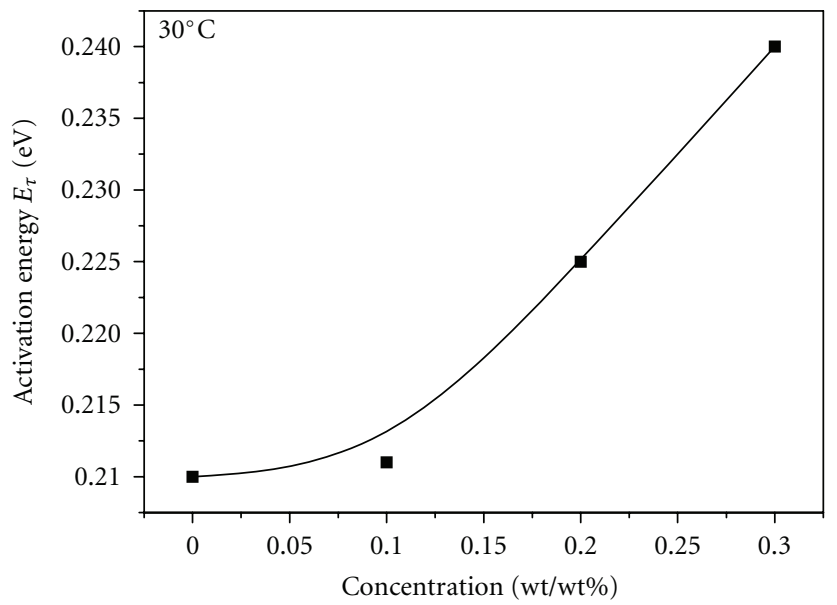

Figure 12: Concentration dependence on activation energy at $30^{\circ} \mathrm{C}$.

\section{Acknowledgments}

The authors gratefully acknowledge the DST, New Delhi for financial support under Project no. SR/FT/CS-50/2011. A. Chaudhary is also thankful to the Ministry of Human Resource Development (MHRD), New Delhi, India for providing financial assistance. 


\section{References}

[1] S. Kaur, S. P. Singh, A. M. Biradar, A. Choudhary, and K. Sreenivas, "Enhanced electro-optical properties in gold nanoparticles doped ferroelectric liquid crystals," Applied Physics Letters, vol. 91, no. 2, Article ID 023120, 2007.

[2] A. Kumar and A. M. Biradar, "Effect of cadmium telluride quantum dots on the dielectric and electro-optical properties of ferroelectric liquid crystals," Physical Review E, vol. 83, no. 4, Article ID 041708, 8 pages, 2011.

[3] S. Kumar, S. K. Pal, P. S. Kumar, and V. Lakshminarayanan, "Novel conducting nanocomposites: synthesis of triphenylene-covered gold nanoparticles and their insertion into a columnar matrix," Soft Matter, vol. 3, no. 7, pp. 896-900, 2007.

[4] Y. Shiraishi, N. Toshima, K. Maeda, H. Yoshikawa, J. Xu, and S. Kobayashi, "Frequency modulation response of a liquidcrystal electro-optic device doped with nanoparticles," Applied Physics Letters, vol. 81, no. 15, pp. 2845-2847, 2002.

[5] Y. Reznikov, O. Buchnev, O. Tereshchenko, V. Reshetnyak, A. Glushchenko, and J. West, "Ferroelectric nematic suspension," Applied Physics Letters, vol. 82, no. 12, pp. 1917-1919, 2003.

[6] C. I. Cheon, L. Li, A. Glushchenko et al., "Electro-optics of liquid crystals doped with ferroelectric nano-powder," SID International Symposium Digest of Technical Papers, vol. 36, pp. 1471-1473, 2005.

[7] F. Haraguchi, K. I. Inoue, N. Toshima, S. Kobayashi, and K. Takatoh, "Reduction of the threshold voltages of nematic liquid crystal electrooptical devices by doping inorganic nanoparticles," Japanese Journal of Applied Physics 2, vol. 46, no. 3335, pp. L796-L797, 2007.

[8] J. Prakash, A. Choudhary, A. Kumar, D. S. Mehta, and A. M. Biradar, "Nonvolatile memory effect based on gold nanoparticles doped ferroelectric liquid crystal," Applied Physics Letters, vol. 93, no. 11, Article ID 112904, 2008.

[9] A. Kumar, J. Prakash, D. S. Mehta, W. Haase, and A. M. Biradar, "Enhanced photoluminescence in gold nanoparticles doped ferroelectric liquid crystals," Applied Physics Letters, vol. 95, no. 2, Article ID 023117, 2009.

[10] X. Tong and Y. Zhao, "Liquid-crystal gel-dispersed quantum dots: reversible modulation of photoluminescence intensity using an electric field," Journal of the American Chemical Society, vol. 129, no. 20, pp. 6372-6373, 2007.

[11] S. W. Lee, C. Mao, C. E. Flynn, and A. M. Belcher, "Ordering of quantum dots, using genetically engineered viruses," Science, vol. 296, no. 5569, pp. 892-895, 2002.

[12] A. Balandin, K. L. Wang, N. Kouklin, and S. Bandyopadhyay, "Raman spectroscopy of electrochemically self-assembled CdS quantum dots," Applied Physics Letters, vol. 76, no. 2, pp. 137$139,2000$.

[13] H. L. Lee, I. A. Mohammed, M. Belmahi, M. B. Assouar, H. Rinnert, and M. Alnot, "Thermal and optical properties of CdS nanoparticles in thermotropic liquid crystal monomers," Materials, vol. 3, pp. 2069-2086, 2010.

[14] A. S. Pandey, R. Dhar, S. Kumar, and R. Dabrowski, "Enhancement of the display parameters of 4 -pentyl-4-cyanobiphenyl due to the dispersion of functionalised gold nano particles," Liquid Crystals, vol. 38, no. 1, pp. 115-120, 2011.

[15] F. V. Podgornov, A. M. Suvorova, A. V. Lapanik, and W. Haase, "Electrooptic and dielectric properties of ferroelectric liquid crystal/single walled carbon nanotubes dispersions confined in thin cells," Chemical Physics Letters, vol. 479, no. 4-6, pp. 206-210, 2009.

[16] A. Chaudhary, P. Malik, R. Mehra, and K. K. Raina, "Electrooptic and dielectric studies of silica doped ferroelectric liquid crystal in SmC* phase," Phase Transitions, vol. 85, pp. 244254, 2012.

[17] P. Malik, A. Chaudhary, R. Mehra, and K. K. Raina, "Electrooptic, thermo-optic and dielectric response of multiwalled carbon nanotube doped ferroelectric liquid crystal thin films," Journal of Molecular Liquids, vol. 165, pp. 7-11, 2012.

[18] A. Kumar, J. Prakash, M. T. Khan, S. K. Dhawan, and A. M. Biradar, "Memory effect in cadmium telluride quantum dots doped ferroelectric liquid crystals," Applied Physics Letters, vol. 97, no. 16, Article ID 163113, 3 pages, 2010.

[19] P. Malik, A. Chaudhary, R. Mehra, and K. K. Raina, "Dielectric studies and memory effect in nanoparticle doped ferroelectric liquid crystal films," Molecular Crystals and Liquid Crystals, vol. 541, pp. 243-251, 2011.

[20] W. K. Lee, J. H. Choi, H. J. Na et al., "Low-power operation of vertically aligned liquid-crystal system via anatase- $\mathrm{TiO}_{2}$ nanoparticle dispersion," Optics Letters, vol. 34, no. 23, pp. 36533655, 2009.

[21] T. Joshi, A. Kumar, J. Prakash, and A. M. Biradar, "Low power operation of ferroelectric liquid crystal system dispersed with zinc oxide nanoparticles," Applied Physics Letters, vol. 96, no. 25, Article ID 253109, 3 pages, 2010.

[22] T. Zhang, C. Zhong, and J. Xu, "CdS-Nanoparticle-doped liquid crystal displays showing low threshold voltage," Japanese Journal of Applied Physics, vol. 48, no. 5, Article ID 055002, 6 pages, 2009.

[23] B. Kinkead and T. Hegmann, "Effects of size, capping agent, and concentration of CdSe and CdTe quantum dots doped into a nematic liquid crystal on the optical and electro-optic properties of the final colloidal liquid crystal mixture," Journal of Materials Chemistry, vol. 20, no. 3, pp. 448-458, 2010.

[24] K. J. Wu, K. C. Chu, C. Y. Chao et al., "CdS nanorods imbedded in liquid crystal cells for smart optoelectronic devices," Nano Letters, vol. 7, no. 7, pp. 1908-1913, 2007.

[25] S. Kundu, J. P. Hill, G. J. Richards et al., "Ultranarrow PbS nanorod-nematic liquid crystal blend for enhanced electrooptic properties," ACS Applied Materials and Interfaces, vol. 2, no. 10, pp. 2759-2766, 2010.

[26] V. V. Danilov, M. V. Artemev, A. V. Baranov, G. M. Ermolaeva, N. A. Utkina, and A. I. Khrebtov, "Fluorescence of semiconductor nanorods in liquid-crystal composites," Optics and Spectroscopy, vol. 105, no. 2, pp. 306-309, 2008.

[27] H. S. Chen, C. W. Chen, C. H. Wang et al., "Color-tunable light-emitting device based on the mixture of CdSe nanorods and dots embedded in liquid-crystal cells," Journal of Physical Chemistry C, vol. 114, no. 17, pp. 7995-7998, 2010.

[28] S. Acharya, S. Kundu, J. P. Hill, G. J. Richards, and K. Ariga, "Nanorod-driven orientational control of liquid crystal for polarization-tailored electro-optic devices," Advanced Materials, vol. 21, no. 9, pp. 989-993, 2009.

[29] I. C. Khoo, K. Chen, and Y. Z. Williams, "Orientational photorefractive effect in undoped and CdSe nanorods-doped nematic liquid crystal-bulk and interface contributions," IEEE Journal on Selected Topics in Quantum Electronics, vol. 12, no. 3, pp. 443-450, 2006.

[30] F. V. Podgornov, A. V. Ryzhkova, and W. Haase, "Influence of gold nanorods size on electro-optical and dielectric properties of ferroelectric liquid crystals," Applied Physics Letters, vol. 97, no. 21, Article ID 212903, 3 pages, 2010.

[31] R. Manohar, A. K. Srivastava, P. K. Tripathi, and D. P. Singh, "Dielectric and electro-optical study of $\mathrm{ZnO}$ nano rods doped ferroelectric liquid crystals," Journal of Materials Science, vol. 46, no. 18, pp. 5969-5976, 2011. 
[32] Y. Yadong and A. P. Alivisatos, "Colloidal nanocrystal synthesis and the organic-inorganic interface," Nature, vol. 437, no. 7059, pp. 664-670, 2005.

[33] X. Nie, R. Lu, H. Xianyu, T. X. Wu, and S. T. Wu, "Anchoring energy and cell gap effects on liquid crystal response time," Journal of Applied Physics, vol. 101, no. 10, Article ID 103110, 5 pages, 2007.

[34] N. Hill, W. E. Vaughan, A. H. Price, and M. Davies, Dielectric Properties and Molecular Behavior, Van Nostrand, New York, NY, USA, 1969.

[35] C. J. F. Bottcher and P. Bordewijk, Theory of Electric Polarization, vol. 2, Elsevier, Amsterdam, The Netherlands, 2nd edition, 1978.

[36] K. S. Cole and R. H. Cole, "Dispersion and absorption in dielectrics I. Alternating current characteristics," The Journal of Chemical Physics, vol. 9, no. 4, pp. 341-351, 1941.

[37] A. S. Pandey, R. Dhar, M. B. Pandey, A. S. Achalkumar, and C. V. Yelamaggad, "Dielectric spectroscopy of unsymmetrical liquid crystal dimers showing wide temperature range TGBA and TGBC* phases," Liquid Crystals, vol. 36, no. 1, pp. 13-19, 2009.

[38] F. Gouda, K. Skarp, and S. T. Lagerwall, "Dielectric studies of the soft mode and Goldstone mode in ferroelectric liquid crystals," Ferroelectrics, vol. 113, pp. 165-206, 1991.

[39] A. Malik, A. Choudhary, J. Prakash, I. Coondoo, and A. M. Biradar, "Enhancement of ferro-para transition in ethanol doped ferroelectric liquid crystals," Journal of Applied Physics, vol. 105, no. 3, Article ID 034105, 5 pages, 2009.

[40] A. K. Srivastava, A. K. Misra, J. P. Shukla, and R. Manohar, "Dielectric and electro-optical properties of dye doped ferroelectric liquid crystal," Physics Letters A, vol. 372, no. 41, pp. 6254-6259, 2008.

[41] A. K. Jonscher, "The 'universal' dielectric response," Nature, vol. 267, no. 5613, pp. 673-679, 1977.

[42] D. K. Pradhan, R. N. P. Choudhary, and B. K. Samantaray, "Studies of dielectric relaxation and ac conductivity behavior of plasticized polymer nanocomposite electrolytes," International Journal of Electrochemical Science, vol. 3, pp. 597-608, 2008.

[43] A. Kovalchuk, L. Dolgov, and O. Yaroshchuk, "Dielectric studies of dispersions of carbon nanotubes in liquid crystals 5CB," Semiconductor Physics, Quantum Electronics \& Optoelectronics, vol. 11, pp. 337-341, 2008. 

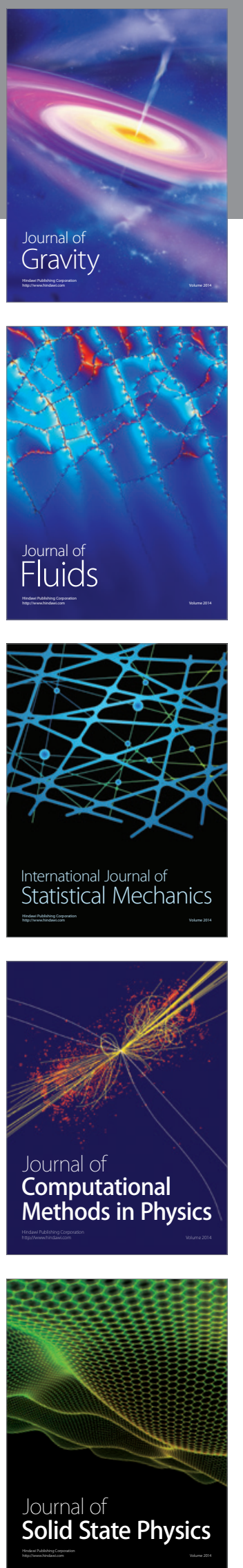

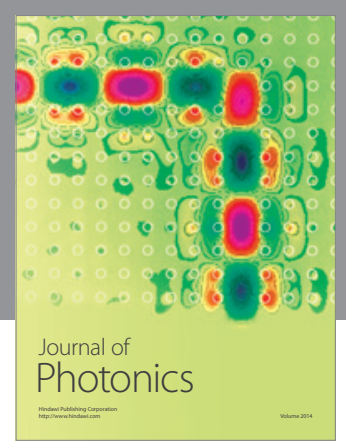

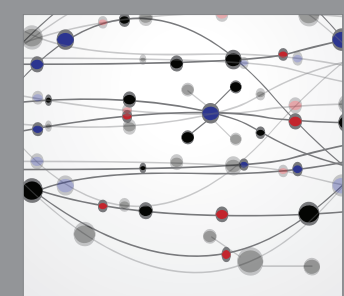

The Scientific World Journal
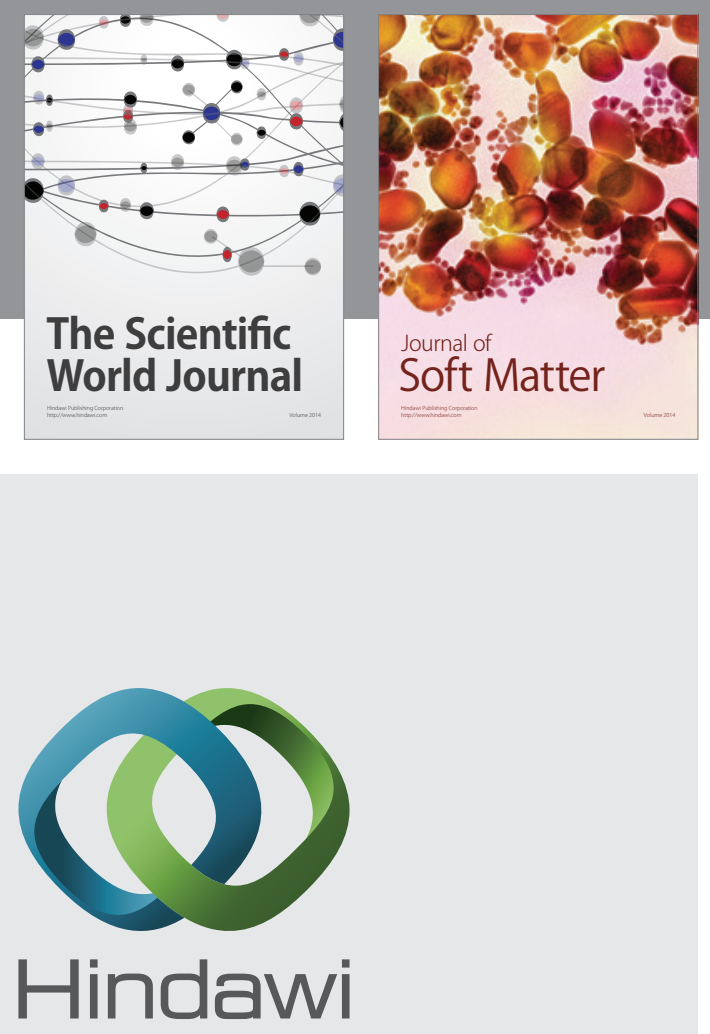

Submit your manuscripts at

http://www.hindawi.com
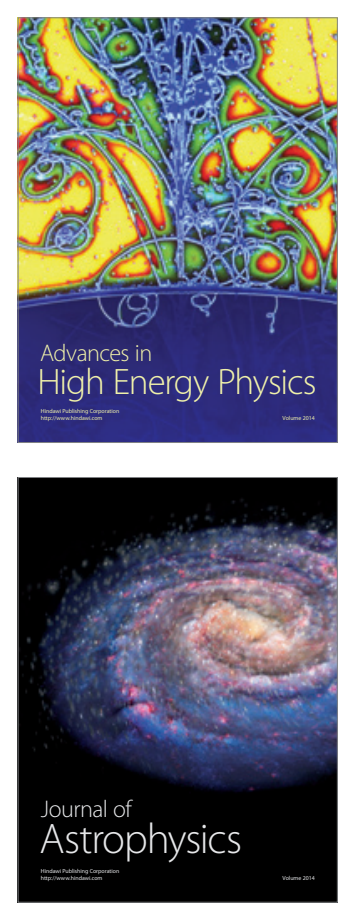
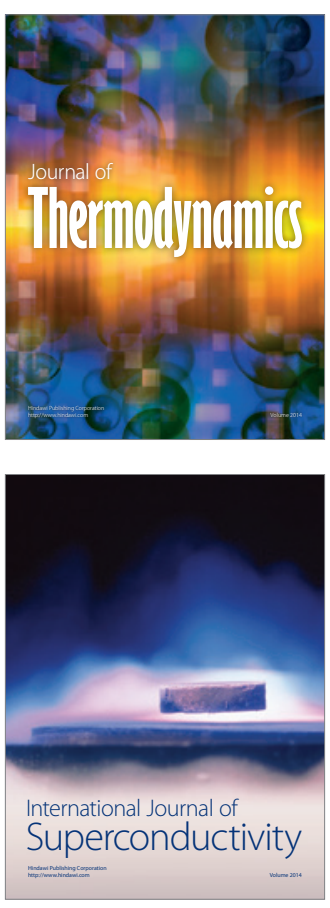
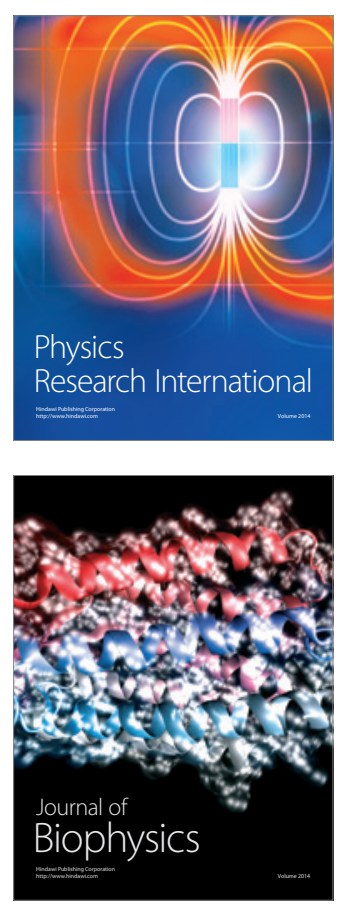
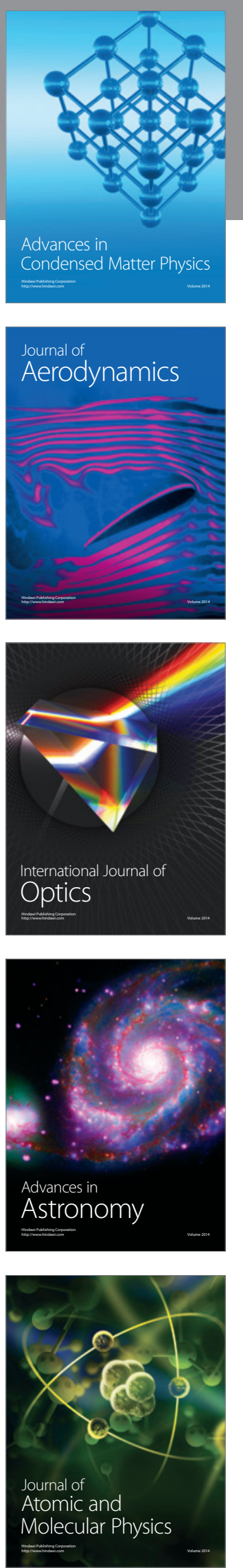